STRUCTURAL BIOLOGY COMMUNICATIONS

ISSN 2053-230X

\section{Cloning, purification and structure determination of the HIV integrase-binding domain of lens epithelium-derived growth factor}

\author{
Clare Hannon, ${ }^{a, b}$ Abimael Cruz-Migoni, ${ }^{a}$ Olga Platonova, ${ }^{a}$ Robin L. Owen, \\ Joanne E. Nettleship, ${ }^{\text {d,e }}$ Ami Miller, ${ }^{\text {a Stephen B. Carr, }}{ }^{\text {f,g }}$ Gemma Harris, ${ }^{\text {g }}$ \\ Terence H. Rabbitts ${ }^{\mathrm{a} *}$ and Simon E. V. Phillips ${ }^{\mathrm{f}} \mathrm{g}_{*}$
}

Received 12 December 2017

Accepted 23 January 2018

Edited by G. G. Privé, University of Toronto, Canada

Keywords: HIV integrase-binding domain; lens epithelium-derived growth factor; human immunodeficiency virus; domain swapping.

PDB reference: HIV integrase-binding domain of lens epithelium-derived growth factor, 5oym

Supporting information: this article has supporting information at journals.iucr.org/f

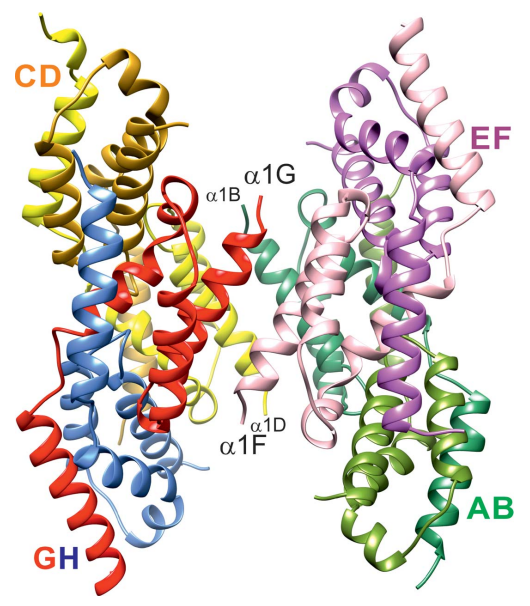

OPEN $\odot$ ACCESS

\begin{abstract}
${ }^{a}$ Weatherall Institute of Molecular Medicine, University of Oxford, John Radcliffe Hospital, Oxford OX3 9DS, England, b West Suffolk Hospital, Hardwick Lane, Bury St Edmunds IP33 2QZ, England, 'Diamond Light Source, Rutherford Appleton Laboratory, Didcot OX11 ODE, England, 'Oxford Protein Production Facility, Research Complex at Harwell, Rutherford Appleton Laboratory, Didcot OX11 OFA, England, ${ }^{\mathbf{e}}$ Division of Structural Biology, Henry Wellcome Building for Genomic Medicine, University of Oxford, Roosevelt Drive, Oxford OX3 7BN, England, 'Department of Biochemistry, University of Oxford, South Parks Road, Oxford OX1 3QU, England, and ${ }^{\mathbf{g}}$ Research Complex at Harwell, Rutherford

Appleton Laboratory, Didcot OX11 OFA, England. *Correspondence e-mail: terence.rabbitts@imm.ox.ac.uk, simon.phillips@rc-harwell.ac.uk
\end{abstract}

Lens epithelium-derived growth factor (LEDGF)/p75 is the dominant binding partner of HIV-1 integrase in human cells. The crystal structure of the HIV integrase-binding domain (IBD) of LEDGF has been determined in the absence of ligand. IBD was overexpressed in Escherichia coli, purified and crystallized by sitting-drop vapour diffusion. X-ray diffraction data were collected at Diamond Light Source to a resolution of $2.05 \AA$. The crystals belonged to space group $P 2_{1}$, with eight polypeptide chains in the asymmetric unit arranged as an unusual octamer composed of four domain-swapped IBD dimers. IBD exists as a mixture of monomers and dimers in concentrated solutions, but the dimers are unlikely to be biologically relevant.

\section{Introduction}

Lens epithelium-derived growth factor (LEDGF) is a transcriptional co-activator that was discovered as a binding partner of HIV integrase (Cherepanov et al., 2003). It was later shown to be essential for the formation of a tripartite complex of MLL (mixed lineage leukaemia; HGNC nomenclature KMT2A) protein, menin (multiple endocrine neoplasia type 1; MEN-1) protein and LEDGF that is implicated in MLL (Cermáková et al., 2014). Epitope mapping shows that the integrase-binding domain (IBD) of LEDGF is also the part of the protein necessary for MLL/menin binding (Cermáková et $a l ., 2014)$. The design of drugs that can interfere with proteinprotein interactions (PPIs) involving IBD would be important for therapy in both AIDS and leukaemias.

Drug screens for small molecules, or for macromolecules such as intracellular antibody fragments, require structural data for in silico design and/or epitope targeting. The structure of IBD has previously been determined in solution by NMR (Cherepanov, Sun et al., 2005) and in X-ray crystal structures of complexes of IBD with HIV integrase as a heterodimer (Cherepanov, Ambrosio et al., 2005) and a tetramer (Hare et $a l ., 2009$ ), with an HIV integrase homologue (Hare \& Cherepanov, 2009) and in complex with menin and MLL (Huang et $a l ., 2012)$. The crystal structure of IBD alone, however, has not been solved in the absence of ligands. In this paper, we report 
the cloning, overexpression, purification and X-ray crystal structure determination of free IBD.

\section{Materials and methods}

\subsection{Macromolecule production}

The sequence encoding the HIV integrase-binding domain (IBD) of LEDGF was PCR-amplified directly from cDNA prepared using an RT-PCR kit with RNA extracted from the T-cell lymphoma cell line VL3-3M2 (Groves et al., 1995). The purified DNA fragment ( $372 \mathrm{bp}$ ) was inserted into the NotI and EcoRI sites of pRK172 vector, encoding an N-terminal His tag, a TEV protease cleavage site and a 24 -amino-acid linker ending with methionine preceding the initial Glu345 of the IBD. Positive clones were confirmed by colony PCR, and plasmid DNA was isolated and purified using a QIAquick plasmid kit (Qiagen, Crawley, England). The correct sequence was confirmed and the plasmid DNA was transformed into Escherichia coli B834 (DE3) cells. For the production of IBD protein, a $50 \mathrm{ml}$ flask containing $10 \mathrm{ml}$ Power Broth Medium (Molecular Dimensions) supplemented with $50 \mu \mathrm{g} \mathrm{ml}^{-1}$ carbenicillin was inoculated with a single colony of the transformed E. coli cells and grown overnight at $310 \mathrm{~K}$ in a shaking incubator at $225 \mathrm{rev} \mathrm{min}^{-1} .8 \mathrm{ml}$ of this culture was used to inoculate 21 flasks each containing 0.51 Power Broth Medium (Molecular Dimensions) supplemented with $50 \mu \mathrm{g} \mathrm{ml}^{-1}$ carbenicillin. Growth was carried out at $310 \mathrm{~K}$ with vigorous aeration until an $\mathrm{OD}_{600}$ of 0.6 was attained and the cultures were induced with isopropyl $\beta$-D-1-thiogalactopyranoside (IPTG) at a final concentration of $0.5 \mathrm{~m} M$. The temperature was reduced to $298 \mathrm{~K}$ and the culture was incubated for an additional $18 \mathrm{~h}$.

The cells were harvested by centrifugation at $5000 \mathrm{~g}$ for $10 \mathrm{~min}$ at $277 \mathrm{~K}$ and lysed using a cell disrupter (Constant Systems Ltd, UK) at $186 \mathrm{MPa}$ in lysis buffer $(50 \mathrm{~m} M$ Tris $\mathrm{pH}$ $7.5,500 \mathrm{mM} \mathrm{NaCl}, 30 \mathrm{~m} M$ imidazole, $0.2 \%$ Tween) supplemented with protease inhibitor (cOmplete EDTA-free tablets, Roche Life Science, UK) and DNase I. Cell debris was removed by centrifugation at $50000 \mathrm{~g}$ for $50 \mathrm{~min}$ at $227 \mathrm{~K}$ (Beckman Coulter Avanti J-26 XP with JA 25.50 rotor) and the supernatant was collected. The protein was purified using an automated IMAC-SEC process on an ÄKTAxpress system (GE Healthcare). Firstly, the supernatant was loaded onto a $1 \mathrm{ml}$ HisTrap FF column (GE Healthcare) and washed using a buffer consisting of $50 \mathrm{~m} M$ Tris $\mathrm{pH} 7.5,500 \mathrm{~m} M \mathrm{NaCl}, 30 \mathrm{~m} M$ imidazole. Elution in a buffer consisting of $50 \mathrm{~m} M$ Tris $\mathrm{pH} 7.5$, $500 \mathrm{~m} M \mathrm{NaCl}, 500 \mathrm{~m} M$ imidazole was followed by direct injection onto a HiLoad Superdex 75 pg 16/60 column (GE Healthcare, UK) and elution in $20 \mathrm{~m} M$ Tris $\mathrm{pH} 7.5,200 \mathrm{~m} M$ $\mathrm{NaCl}, 1 \mathrm{~m} M$ TCEP; fractions were collected and analysed by SDS-PAGE. Fractions containing the IBD protein were concentrated to $2 \mathrm{ml}$ using an Amicon Ultra- 15 concentration device with a $3 \mathrm{kDa}$ molecular-weight cutoff before the addition of a $0.1 \times$ volume of TEV protease $\left(1 \mathrm{mg} \mathrm{ml}^{-1}\right)(\mathrm{a}$ kind gift from the Membrane Protein Laboratory, Diamond Light Source, UK). The sample was incubated overnight at
$277 \mathrm{~K}$ to allow proteolytic cleavage of the His tag. The protein was further purified by passing it through a HisTrap FF column (reverse IMAC) to remove the tag and His-tagged TEV protease from the IBD protein. Finally, the IBD protein was concentrated to $6.5 \mathrm{mg} \mathrm{ml}^{-1}$ for crystallization using an Amicon Ultra-15 centrifugal concentrator with a $3 \mathrm{kDa}$ molecular-weight cutoff. The purity was estimated to be greater than $95 \%$ (as determined by SDS-PAGE). Approximately $0.1 \mathrm{mg}$ pure protein was obtained from 11 of culture.

The protein was analysed by intact protein mass spectrometry (Nettleship et al., 2008) and its molecular weight was found to be $11882 \mathrm{Da}$, compared with the calculated value of $11881.66 \mathrm{Da}$ based on its sequence. During purification the His-tagged IBD protein eluted from the HiLoad Superdex 75 pg $16 / 60$ column at $78.05 \mathrm{ml}$, suggesting that it is a monomer in solution when compared with calibration standards (GE Healthcare).

In the preparation of IBD for analytical centrifugation, pRK172-His-TEV-IBD was transformed into E. coli C41 (DE3) cells. A single colony was grown overnight in $80 \mathrm{ml} \mathrm{LB}$

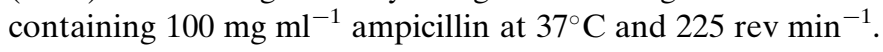
$8 \mathrm{ml}$ of the overnight seed culture was used to inoculate $8 \times 11$ LB containing $100 \mathrm{mg} \mathrm{ml}^{-1}$ ampicillin. The cells were grown at $30^{\circ} \mathrm{C}$ at $225 \mathrm{rev} \mathrm{min}^{-1}$ until an $\mathrm{OD}_{600}$ of 0.8 was reached. Protein expression was induced by the addition of $0.1 \mathrm{mM}$ IPTG and the cells were incubated at $18^{\circ} \mathrm{C}$ and $225 \mathrm{rev} \mathrm{min}^{-1}$ for a further $3 \mathrm{~h}$. The cells were harvested by centrifugation and the pellets were resuspended in lysis buffer $(50 \mathrm{~m} M$ Tris $\mathrm{pH} 7.5,500 \mathrm{~m} M \mathrm{NaCl}, 0.2 \%$ Tween $20,20 \mathrm{~m} M$ imidazole) containing EDTA-free protease-inhibitor cocktail tablets (Roche, Germany), DNase I and $1 \mathrm{mM} \mathrm{MgSO}_{4}$. The cells were lysed using a cell disruptor (Constant Systems Ltd, UK) at $172 \mathrm{MPa}$ and $4^{\circ} \mathrm{C}$ and the sample was clarified by centrifugation at $23000 \mathrm{rev} \min ^{-1}$ for $1 \mathrm{~h}$. The cell lysate was incubated with Ni-NTA agarose (Qiagen, UK) for $2 \mathrm{~h}$ at $4^{\circ} \mathrm{C}$. The beads were applied onto a gravity-flow column and were washed with $50 \mathrm{~m} M$ Tris pH 7.4, $500 \mathrm{mM} \mathrm{NaCl}$ and $20 \mathrm{~m} M$ imidazole. Soluble His-TEV-IBD was eluted with $30 \mathrm{ml}$ $50 \mathrm{~m} M$ Tris pH 7.4, $500 \mathrm{~m} M \mathrm{NaCl}$ and $300 \mathrm{~m} M$ imidazole. HisTEV protease was added to the eluate at a concentration of $17.5 \mu \mathrm{g} \mathrm{ml}^{-1}$ and the mixture was dialysed against $20 \mathrm{mM}$ Tris $\mathrm{pH} 7.5,200 \mathrm{mM} \mathrm{NaCl}$ overnight at $4^{\circ} \mathrm{C}$. To remove the cleaved His-TEV, uncleaved His-TEV-IBD and His-TEV protease, the sample was incubated with Ni-NTA beads for $1 \mathrm{~h}$ at room temperature. The beads were again applied onto a gravity-flow column and the flowthrough was collected. The IBD sample was concentrated to $2 \mathrm{ml}$ and was further purified by gel filtration using a Superdex 75 16/600 column (GE Healthcare, UK) with $20 \mathrm{~m} M$ Tris $\mathrm{pH} 7.5,200 \mathrm{~m} M \mathrm{NaCl}, 1 \mathrm{~m} M$ TCEP. Protein-containing fractions were pooled and concentrated for analytical ultracentrifugation. Approximately $1.5 \mathrm{ml}$ pure protein was obtained from 11 of culture.

The oligomeric state of the protein at higher concentrations was analysed by analytical ultracentrifugation (AUC). For characterization of the IBD sample, sedimentation-velocity scans were recorded for a twofold protein-dilution series, starting from $6.5 \mathrm{mg} \mathrm{m}^{-1}$. All AUC experiments were 
Table 1

Macromolecule-production information.

\begin{tabular}{|c|c|}
\hline Source organism & Human \\
\hline DNA source & $\begin{array}{l}\text { cDNA prepared with the ProtoScript II } \\
\text { RT-PCR kit with RNA extracted from } \\
\text { the T-cell lymphoma cell line VL3-3M2 }\end{array}$ \\
\hline Forward primer & $\begin{array}{l}\text { ATTGCGGCCGCAATGGTTAAGAAAGTGGAG } \\
\text { AAGAAGCGA }\end{array}$ \\
\hline Reverse primer & $\begin{array}{l}\text { ATAGAATTCTTATTCACCAACCAAAAACAT } \\
\text { ATT }\end{array}$ \\
\hline Cloning vector & pRK172 \\
\hline Expression vector & pRK172 \\
\hline $\begin{array}{l}\text { Expression host } \\
\text { (crystallization) }\end{array}$ & E. coli strain B834 (DE3) \\
\hline $\begin{array}{l}\text { Expression host (analytical } \\
\text { ultracentrifugation) }\end{array}$ & E. coli strain $\mathrm{C} 41$ (DE3) \\
\hline $\begin{array}{l}\text { Complete amino-acid sequence } \\
\text { of the construct produced }\end{array}$ & $\begin{array}{l}\text { MVKKVEKKRHHHHHHGSENLYFQGGSMGSG } \\
\text { GGGSGGGGSGGGGAAAMETSMDSRLQRI } \\
\text { HAEIKNSLKIDNLDVNRCIEALDELASL } \\
\text { QVTMQQAQKHTEMITTLKKIRRFKVSQV } \\
\text { IMEKSTMLYNKFKNMFLVGE }\end{array}$ \\
\hline
\end{tabular}

performed at $50000 \mathrm{rev}_{\mathrm{min}^{-1}}$ using a Beckman XL-I analytical ultracentrifuge with an An-50 Ti rotor at $20^{\circ} \mathrm{C}$. Data were recorded using the absorbance (at $280 \mathrm{~nm}$ ) and interference optical detection systems. The density and viscosity of the buffer was measured experimentally using a DMA $5000 \mathrm{M}$ densitometer equipped with a Lovis 200ME viscometer module. The partial specific volume of the protein construct was calculated using SEDFIT (Schuck, 2000) from the aminoacid sequence. Data were processed using SEDFIT, fitting to the $c(s)$ model. Figures were made using GUSSI (Brautigam, 2015).

Cloning and protein-purification information is summarized in Table 1.
Table 2

Crystallization.

\begin{tabular}{ll}
\hline Method & Vapour diffusion, sitting drop \\
Plate type & 96 -well 2-drop MRC crystallization plates \\
Temperature $(\mathrm{K})$ & 294 \\
Protein concentration $\left(\mathrm{mg} \mathrm{ml}^{-1}\right)$ & 6.5 \\
Buffer composition of protein & $20 \mathrm{~m} M$ Tris pH 7.5, 200 mM NaCl, \\
$\quad$ solution & $1 \mathrm{~m} M$ TCEP \\
Composition of reservoir solution & $0.2 M$ sodium fluoride, $0.1 M$ bis-tris \\
\multicolumn{2}{c}{ propane pH 8.5, 20\% $(w / v)$ PEG 3350 } \\
Volume and ratio of drop & $100 \mathrm{nl}, 1: 1$ \\
Volume of reservoir $(\mu \mathrm{l})$ & 95
\end{tabular}

\subsection{Crystallization}

Crystallization screening experiments were performed by sitting-drop vapour diffusion using a Cartesian MicroSys crystallization robot (Digilab Ltd, Huntingdon, England) followed by incubation at $294 \mathrm{~K}$ (Walter et al., 2005). The protein concentration was calibrated from the analytical ultracentrifugation results. Crystals were observed after $24 \mathrm{~h}$ in a number of crystallization drops, with the best crystals being obtained using the conditions shown in Table 2.

\subsection{Data collection and processing}

Crystals were harvested and transferred to a 2:1 mixture of crystallization buffer and glycerol as a cryoprotectant for a few seconds before flash-cooling in liquid nitrogen. Diffraction data were collected from a single crystal with dimensions of $25 \times 25 \times 90 \mu \mathrm{m}$ at $100 \mathrm{~K}$ using a wavelength of $0.9778 \AA$ on beamline I24 at Diamond Light Source (DLS, UK) with a PILATUS2 6M hybrid pixel-array detector. Each diffraction image corresponded to an oscillation angle of $0.2^{\circ}$ with

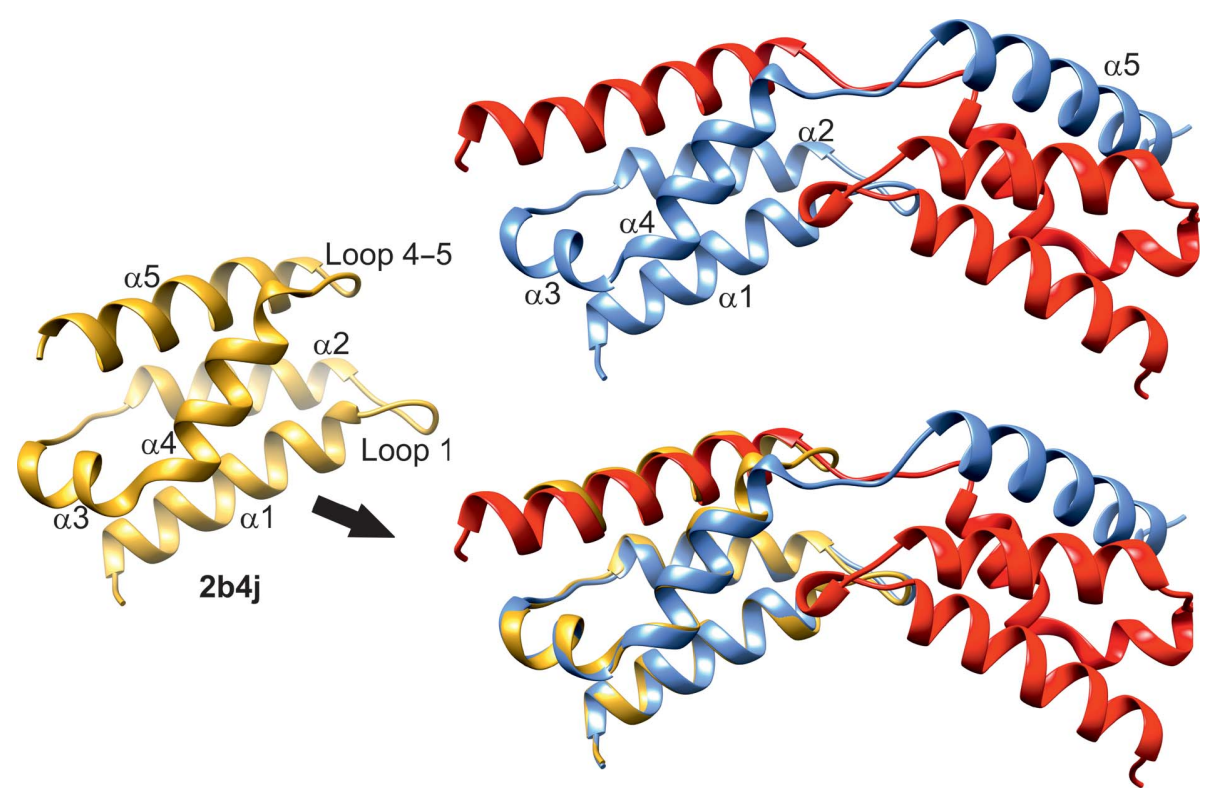

Figure 1

IBD domain-swapped dimer (chain G, red; chain H, blue) viewed perpendicular to the local twofold axis (top). The IBD domain from the human integrase complex (PDB entry 2b4j) is shown in yellow (left), together with its superposition on chain $\mathrm{H}$ (bottom). All helices superimpose well, with the only significant disruption in loop 4-5. Figures were prepared with UCSF Chimera (Pettersen et al., 2004). 
Table 3

Data collection and processing.

Values in parentheses are for the outer shell.

\begin{tabular}{|c|c|}
\hline Diffraction source & Beamline I24, DLS \\
\hline Wavelength (ঐ) & 0.9778 \\
\hline Temperature (K) & 100 \\
\hline Detector & PILATUS2 6M \\
\hline Crystal-to-detector distance (mm) & 390 \\
\hline Rotation range per image $\left(^{\circ}\right)$ & 0.2 \\
\hline Total rotation range $\left({ }^{\circ}\right)$ & 125.8 \\
\hline Exposure time per image (s) & 0.2 \\
\hline Space group & $P 2_{1}$ \\
\hline$a, b, c(\AA)$ & $71.18,54.81,118.00$ \\
\hline$\alpha, \beta, \gamma\left({ }^{\circ}\right)$ & $90,91.23,90$ \\
\hline Mosaicity $\left({ }^{\circ}\right)$ & 0.103 \\
\hline Resolution range $(\AA)$ & $54.81-2.05(2.16-2.05)$ \\
\hline Total No. of reflections & $132649(19728)$ \\
\hline No. of unique reflections & $55617(8059)$ \\
\hline Completeness (\%) & $97.1(97.0)$ \\
\hline Multiplicity & $2.4(2.4)$ \\
\hline$\langle I / \sigma(I)\rangle$ & $8.6(1.7)$ \\
\hline $\mathrm{CC}_{1 / 2}$ & $0.997(0.510)$ \\
\hline$R_{\text {r.i.m. }}$ & $0.097(0.796)$ \\
\hline Overall $B$ factor from Wilson plot $\left(\AA^{2}\right)$ & 28.8 \\
\hline
\end{tabular}

diffraction observed to a maximum resolution of $2.05 \AA$. Data reduction was performed using $X D S$ (Kabsch, 2010).

Data-collection and processing information is shown in Table 3.

\subsection{Structure solution and refinement}

The crystals of IBD belonged to space group $P 2_{1}$, with unitcell parameters $a=71.18, b=54.81, c=118.00 \AA$ A,$\beta=91.23^{\circ}$, and contained eight molecules per asymmetric unit, giving a Matthews coefficient and solvent content of $2.43 \AA^{3} \mathrm{Da}^{-1}$ and $49.48 \%$, respectively (Matthews, 1977). Initial phase estimates were calculated using Phaser (McCoy et al., 2007) from the CCP4 software suite (Winn et al., 2011) with the IBD domain from PDB entry $2 \mathrm{~b} 4 \mathrm{j}$ (Cherepanov, Sun et al., 2005) as a search model. The structure was refined using iterative cycles of REFMAC5 (Murshudov et al., 2011) followed by manual rebuilding of the model using Coot (Emsley et al., 2010). The electron density clearly showed all five $\alpha$-helices, but the loop linking helices $\alpha 4$ and $\alpha 5$ (loop 4-5; residues 405-409) was less well defined and did not follow the expected path of the loop, instead leading to density belonging to an adjacent IBD molecule. As refinement progressed it became clear that helix $\alpha 5$ in each IBD domain actually belonged to a neighbouring IBD chain, and that there was a domain swap with concomitant reorganization of loop 4-5 (Fig. 1). The octamer in the asymmetric unit is composed of four domain-swapped dimers with good overall noncrystallographic symmetry (NCS), and eightfold NCS-averaged maps were used in initial model building, with eightfold NCS restraints applied in refinement (the r.m.s. fit between equivalent $\mathrm{C}^{\alpha}$ atoms in the final refined model is $0.70 \AA$ ). Evidence of disorder, however, remained in loop $4-5$, and helix $\alpha 5$ did not obey the NCS as faithfully as the rest of the domain. The two loop 4-5 regions in each domainswapped dimer do not obey the local twofold NCS and, in particular, the two Phe406 side chains would clash with each other if both were in the same conformation. There are at least
Table 4

Structure refinement.

Values in parentheses are for the outer shell.

\begin{tabular}{ll}
\hline Resolution range $(\AA)$ & $14.98-2.05(2.102-2.050)$ \\
Completeness (\%) & 96.3 \\
$\sigma$ Cutoff & None \\
No. of reflections, working set & $52601(3819)$ \\
No. of reflections, test set & $2800(200)$ \\
Final $R_{\text {cryst }}$ & $0.182(0.297)$ \\
Final $R_{\text {free }}$ & $0.236(0.322)$ \\
No. of non-H atoms & \\
$\quad$ Protein & 5606 \\
$\quad$ Solvent & 445 \\
$\quad$ Total & 6129 \\
R.m.s. deviations & \\
$\quad$ Bonds $(\AA)$ & 0.017 \\
$\quad$ Angles $\left({ }^{\circ}\right)$ & 1.88 \\
Average $B$ factors $\left(\AA^{2}\right)$ & \\
$\quad$ Protein & 38.2 \\
$\quad$ Water & 40.0 \\
Ramachandran plot & \\
$\quad$ Favoured regions $(\%)$ & 97.5 \\
$\quad$ Additionally allowed $(\%)$ & 2.5 \\
\hline
\end{tabular}

two conformations for loop 4-5, and inspection of each dimer in turn showed a majority population of one conformation in one subunit and of the other in the related subunit, leading to asymmetry in each dimer. The four dimers (chains $A B, C D$, $\mathrm{EF}$ and $\mathrm{GH}$ ) were rebuilt with the asymmetric linkers, and refinement proceeded applying full eightfold NCS restraints to residues 345-403 (helices $\alpha 1-\alpha 4$ ) and, separately, to residues 408-431 (helices $\alpha 5$ ), with fourfold NCS restraints applied to residues 404-407 in chains A, C, F and G and chains B, D, E and $\mathrm{H}$, respectively. Residual density remains around loop $4-5$, indicating a degree of disorder. The $\mathrm{N}$-terminal linker regions preceding the IBD in the expression construct, and 24 of the C-terminal residues in the IBD octamer were not visible in the electron density, so that the final model lacks 209 disordered residues that were shown to be present by mass spectrometry.

The final refined model has crystallographic $R_{\text {work }}$ and $R_{\text {free }}$ values of 18.2 and $23.6 \%$, respectively. The quality of the structure was evaluated using MolProbity (Chen et al., 2010), with a MolProbity score of 1.48, corresponding to the 97th percentile for structures at comparable resolution. Figures were prepared using UCSF Chimera (Pettersen et al., 2004). Coordinates and structure factors have been deposited in the Protein Data Bank (http://www.rcsb.org) with accession code 5 oym.

Data-reduction and refinement statistics are shown in Table 4.

\section{Results and discussion}

The HIV integrase-binding domain (IBD) of LEDGF has been cloned, expressed and purified, and its crystal structure has been determined to $2.05 \AA$ resolution. The electrondensity map was of good quality for the eight crystallographically independent polypeptide chains $(\mathrm{A}-\mathrm{H})$ in the asymmetric unit, allowing residues $345-429$ to be built in all of 
them. The IBD domain consists of four long $\alpha$-helices $(\alpha 1, \alpha 2$, $\alpha 4$ and $\alpha 5)$ arranged as a helical bundle, with a fifth short helix, $\alpha 3$, linking $\alpha 2$ and $\alpha 4$ (Fig. 1). The remaining links between helices are made by two short loops: loop 1-2 and loop 4-5. The crystal structure of the IBD domain has previously been reported in complexes with human HIV integrase (Cherepanov, Ambrosio et al., 2005; PDB entry 2b4j) and an HIV integrase homologue (Hare \& Cherepanov, 2009; PDB entry $3 \mathrm{f} 9 \mathrm{k}$ ). The structure of the free IBD domain has also been solved in solution by NMR (Cherepanov, Sun et al., 2005; PDB entry $1 \mathrm{z} 9 \mathrm{e}$ ). All of the published IBD structures have a single, very similar, compact domain, such as that of PDB entry $2 b 4$ j shown in Fig. 1, but the free IBD crystal structure reported here shows a domain-swapped dimer. Reorganization of loop 4-5 allows $\alpha 5$ of each IBD to cross over and occupy its normal location relative to the other domain (Fig. 1). A least-squares fit of the $\mathrm{C}^{\alpha}$ atoms for residues $347-405$ (helices $\alpha 1-\alpha 4$ ) and 410-427 (helix $\alpha 5$ ) of PDB entry $2 \mathrm{~b} 4 \mathrm{j}$ to residues 347-405 (helices $\alpha 1-\alpha 4$ ) of IBD chain $\mathrm{G}$ and $410-427$ (helix $\alpha 5$ ) of IBD chain $\mathrm{H}$ gives an r.m.s deviation of $0.49 \AA$, showing that the packing of the swapped helix $\alpha 5$ closely matches its location in the monomeric $2 \mathrm{~b} 4 \mathrm{j}$ domain.

In the crystal structure, four domain-swapped IDB dimers further assemble into octamers with 222 symmetry (Fig. 2). Interestingly, the local twofold axes of the IBD dimers do not pass through the centre of the octamer and are therefore not part of the point group, so that the octamer corresponds to a symmetric tetramer of dimers. Pairs of domain-swapped IBD dimers pack tightly together to form two equivalent tetramers: $\mathrm{AB} / \mathrm{EF}$ and $\mathrm{CD} / \mathrm{GH}$. In the $\mathrm{AB} / \mathrm{EF}$ tetramer interfaces $\alpha 3 \mathrm{~B}$, $\alpha 4 \mathrm{~B}$ and the C-terminus of $\alpha 5 \mathrm{~A}$ pack against $\alpha 1 \mathrm{E}$ and $\alpha 2 \mathrm{E}$, while the symmetry-related $\alpha 3 \mathrm{~F}, \alpha 4 \mathrm{~F}$ and the C-terminus of $\alpha 5 \mathrm{E}$ pack against $\alpha 1 \mathrm{~A}$ and $\alpha 2 \mathrm{~A}$, with a similar arrangement in the $\mathrm{CD} / \mathrm{GH}$ tetramer. The two tetramers associate more loosely via the $\mathrm{N}$-terminal helices $\alpha 1 \mathrm{~B}, \alpha 1 \mathrm{D}, \alpha 1 \mathrm{~F}$ and $\alpha 1 \mathrm{G}$ of chains $\mathrm{B}, \mathrm{D}, \mathrm{F}$ and $\mathrm{G}$, which are not buried in the tetramer interfaces, to form the octamer.

Domain swapping in proteins is not uncommon, and has been reviewed by Liu \& Eisenberg (2002). An online database of domain-swapped structures (http://caps.ncbs.res.in/3dswap; Shameer et al., 2010) shows 293 entries in the PDB. While domain swapping is sometimes functional, and pathological in the case of amyloid proteins, there are many cases where it is an artefact, frequently where a domain has been separated from the rest of a larger protein. These cases usually involve the $\mathrm{N}$ - or $\mathrm{C}$-termini, and it has been suggested that this can occur under appropriate conditions for virtually any protein with an unconstrained terminus (Liu \& Eisenberg, 2002; Bonjack-Shterengartz \& Avnir, 2017; Gronenborn, 2009).

In the case of IBD, $\alpha 5$ does not appear to be unconstrained, but may be destabilized by removal of the domain from the rest of the LEDGF protein. The 'hinge loop' is the point of exchange in domain-swapped proteins and frequently forms either a $\beta$-strand or $\alpha$-helix (Liu \& Eisenberg, 2002). Loop 4-5 in IBD corresponds to the 'hinge loop', and it adopts an extended $\beta$-strand conformation for residues $405-409$ in the domain-swapped dimer. In the monomeric forms, such as PDB entry $2 \mathrm{~b} 4 \mathrm{j}$, it forms a type I $\beta$-turn at residues $406-409$, and the only significant conformation change in the domain-swapped form is the conversion of Lys407 and Val408 from $\alpha$-helical to $\beta$-strand $\varphi$ and $\psi$ angles (Fig. 3). In the monomeric form, the side chain of Phe 406 packs against the end of the helical bundle, with Val408 lying on top at the surface of the loop. In the domain-swapped dimer, the phenyl ring of Phe406 is replaced by the side chain of Val408 from the other subunit, with its corresponding Phe406 phenyl ring packed behind it
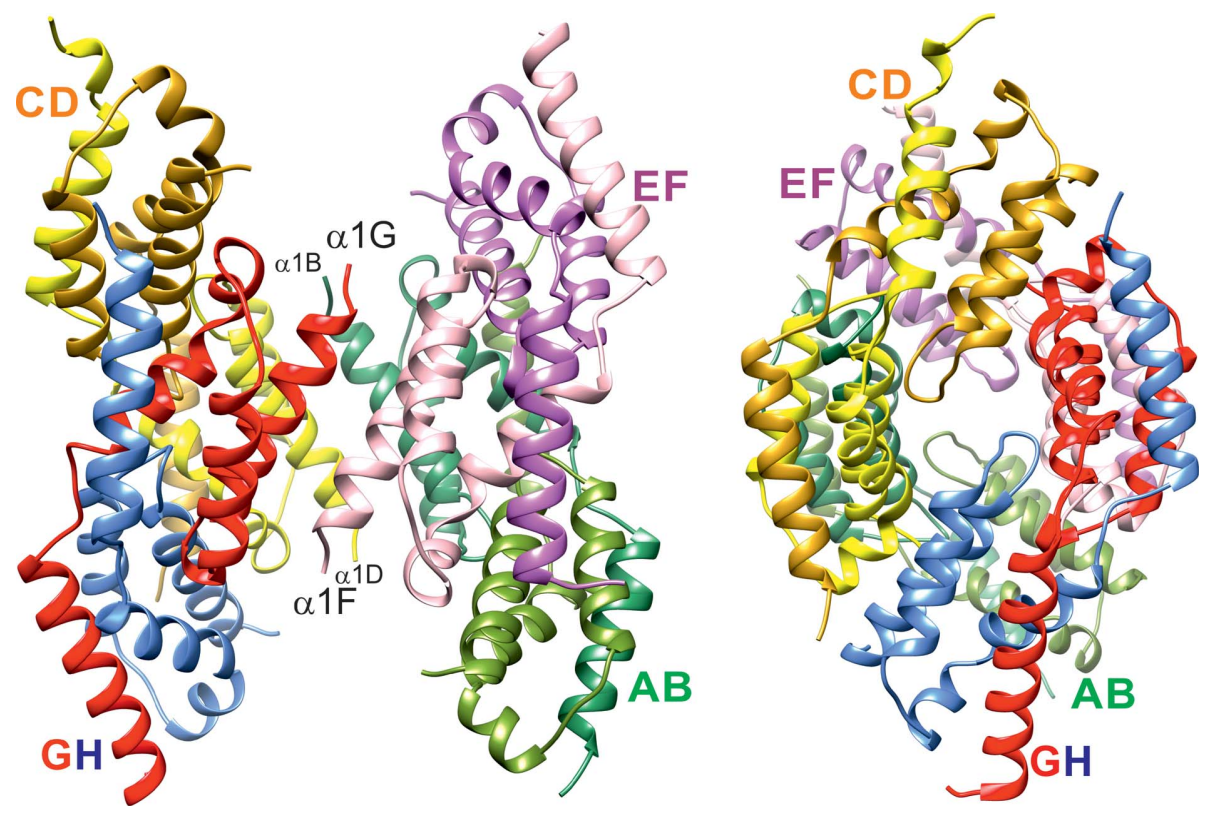

Figure 2

The IBD octamer viewed along two perpendicular twofold axes. Pairs of domain-swapped dimers assemble into tightly packed tetramers $\mathrm{AB} / \mathrm{EF}$ and $\mathrm{CD} /$ $\mathrm{GH}$ (right). The two tetramers associate less strongly via contacts between the N-terminal helices of chains $\mathrm{B}, \mathrm{D}, \mathrm{F}$ and $\mathrm{G}$. 


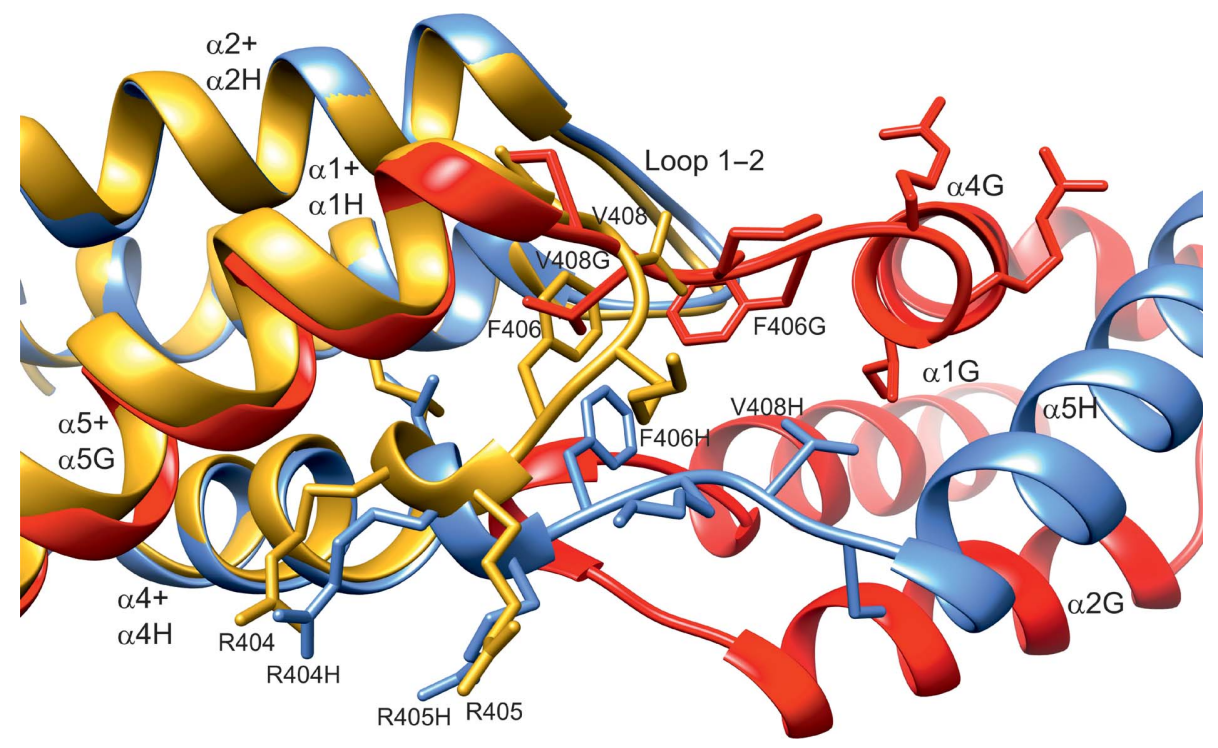

Figure 3

Close-up of the domain-exchange 'hinge loop' of the dimer (chain G, red; chain H, blue) viewed approximately along the local twofold axis, with the superimposed IBD domain from the human integrase complex (PDB entry 2b4j) shown in yellow. Residue and helix labels without chain identifiers correspond to PDB entry $2 \mathrm{~b} 4 \mathrm{j}$. The side chain of Phe 406 in the $2 \mathrm{~b} 4 \mathrm{j}$ monomer is replaced by Val408G of the opposing subunit in the dimer.

(Fig. 3). Steric crowding at the crossover point in the dimer prevents the two opposing Phe406 side chains from adopting the same conformation, with their rotamers differing principally in $\chi_{2}$, leading to a breakdown of twofold symmetry and the disorder that is observed in electron-density maps.

The observation of domain-swapped dimers in the crystal raises the question of whether the dimers are present in solution or are purely an artefact of crystallization. Analytical ultracentrifugation (AUC) of IBD solutions at a range of concentrations in a buffer similar to that used for crystallization showed the presence of dimers at concentrations greater than $3 \mathrm{mg} \mathrm{ml}^{-1}$. Fig. 4 shows sedimentation-coefficient distributions of IBD obtained from the interference data in

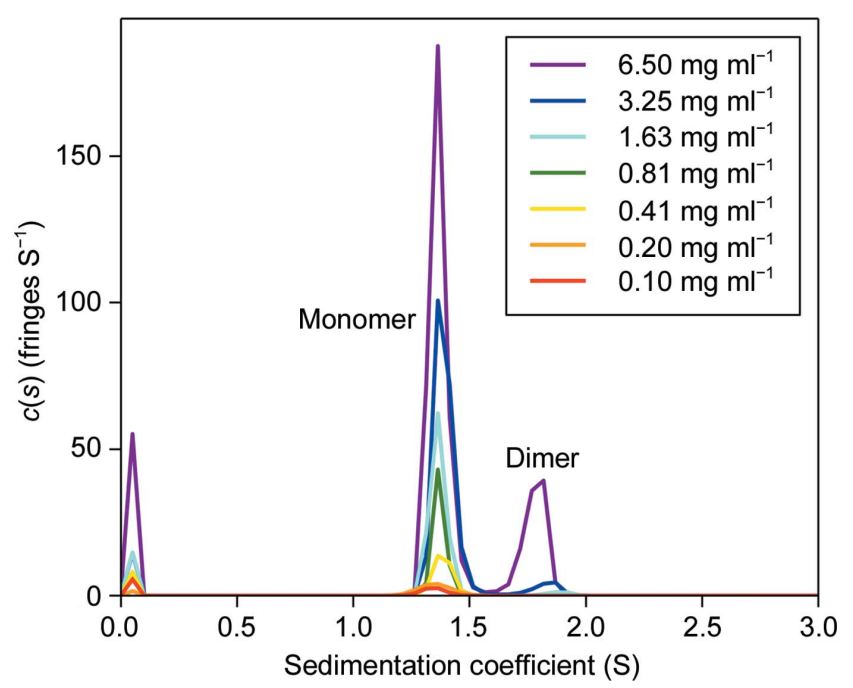

Figure 4

Sedimentation-coefficient distributions of IBD at a range of concentrations. There is clear evidence of dimer formation above $3 \mathrm{mg} \mathrm{ml}^{-1}$.
AUC and, although the self-association is not saturated, implies a $K_{\mathrm{d}}$ for dimer formation of approximately $2 \mathrm{mM}$. It is clear that dimerization is a property of IBD at millimolar concentrations and is not induced by crystallization. There is no evidence, however, of the more loosely packed octamers in solution, and these may only exist in the crystal.

The IBD structure was determined as a target for structurebased drug design in a study aimed at inhibiting proteinprotein interaction between LEDGF and HIV integrase as a strategy for antiviral treatment for AIDS. A single VH antibody domain was isolated that binds to LEGDF and blocks the binding of HIV integrase (Bao et al., 2017; Tanaka \& Rabbitts, 2010). In the integrase complex, the interface between the integrase and IBD is the surface formed by loops 1-2 and 4-5 (Cherepanov, Ambrosio et al., 2005; PDB entry $2 \mathrm{~b} 4 \mathrm{j})$. The VH domain also binds IBD, and the crystal structure of the VH-IBD complex shows the same binding site on IBD as the integrase (Bao et al., 2017; PDB entry 5n88). The domain-swapped dimer in the crystal, however, does not present the same binding site as the monomer at loops 1-2 and $4-5$, showing that it is not the intracellular form of IBD. Caution should therefore be used in the 'divide-and-rule' strategy that employs isolated domains of larger proteins as surrogates for structure-based design.

\section{Acknowledgements}

We are grateful for access to Diamond Light Source beamline I24, where the data were collected.

\section{Funding information}

Funding for this research was provided by: Medical Research Council (grant No. MR/J000612/1 to Terence H. Rabbitts; grant No. MR/K018779/1 to David I. Stuart); Bloodwise (grant 
No. 12051 to Terence H. Rabbitts); Candlelighters (studentship No. 2008-2011 to Clare Hannon); Wellcome Trust (grant No. $099246 / Z / 12 / Z$ to Terence H. Rabbitts).

\section{References}

Bao, L., Hannon, C., Cruz-Mignoni, A., Ptchelkine, D., Sun, M., Miller, A., Bunjobpol, W., Quevedo, C., Derveni, M., Chambers, J. S., Simmons, A., Phillips, S. E. V. \& Rabbitts, T. H. (2017). Sci. Rep. 7, 16869.

Bonjack-Shterengartz, M. \& Avnir, D. (2017). PLoS One, 12, e0180030.

Brautigam, C. A. (2015). Methods Enzymol. 562, 109-133.

Cermáková, K., Tesina, P., Demeulemeester, J., El Ashkar, S., Méreau, H., Schwaller, J., Rezáčová, P., Veverka, V. \& De Rijck, J. (2014). Cancer Res. 74, 5139-5151.

Chen, V. B., Arendall, W. B., Headd, J. J., Keedy, D. A., Immormino, R. M., Kapral, G. J., Murray, L. W., Richardson, J. S. \& Richardson, D. C. (2010). Acta Cryst. D66, 12-21.

Cherepanov, P., Ambrosio, A. L., Rahman, S., Ellenberger, T. \& Engelman, A. (2005). Proc. Natl Acad. Sci. USA, 102, 17308-17313.

Cherepanov, P., Maertens, G., Proost, P., Devreese, B., Van Beeumen, J., Engelborghs, Y., De Clercq, E. \& Debyser, Z. (2003). J. Biol. Chem. 278, 372-381.

Cherepanov, P., Sun, Z.-Y. J., Rahman, S., Maertens, G., Wagner, G. \& Engelman, A. (2005). Nature Struct. Mol. Biol. 12, 526-532.

Emsley, P., Lohkamp, B., Scott, W. G. \& Cowtan, K. (2010). Acta Cryst. D66, 486-501.

Gronenborn, A. M. (2009). Curr. Opin. Struct. Biol. 19, 39-49.
Groves, T., Katis, P., Madden, Z., Manickam, K., Ramsden, D., Wu, G. \& Guidos, C. J. (1995). J. Immunol. 154, 5011-5022.

Hare, S. \& Cherepanov, P. (2009). Viruses, 1, 780-801.

Hare, S., Di Nunzio, F., Labeja, A., Wang, J., Engelman, A. \& Cherepanov, P. (2009). PLoS Pathog. 5, e1000515.

Huang, J., Gurung, B., Wan, B., Matkar, S., Veniaminova, N. A., Wan, K., Merchant, J. L., Hua, X. \& Lei, M. (2012). Nature (London), 482, 542-546.

Kabsch, W. (2010). Acta Cryst. D66, 125-132.

Liu, Y. \& Eisenberg, D. (2002). Protein Sci. 11, 1285-1299.

Matthews, B. W. (1977). The Proteins, edited by H. Neurath \& R. L. Hill, pp. 468-477. New York: Academic Press.

McCoy, A. J., Grosse-Kunstleve, R. W., Adams, P. D., Winn, M. D., Storoni, L. C. \& Read, R. J. (2007). J. Appl. Cryst. 40, 658674.

Murshudov, G. N., Skubák, P., Lebedev, A. A., Pannu, N. S., Steiner, R. A., Nicholls, R. A., Winn, M. D., Long, F. \& Vagin, A. A. (2011). Acta Cryst. D67, 355-367.

Nettleship, J. E., Brown, J., Groves, M. R. \& Geerlof, A. (2008). Methods Mol. Biol. 426, 299-318.

Pettersen, E. F., Goddard, T. D., Huang, C. C., Couch, G. S., Greenblatt, D. M., Meng, E. C. \& Ferrin, T. E. (2004). J. Comput. Chem. 25, 1605-1612.

Schuck, P. (2000). Biophys. J. 78, 1606-1619.

Shameer, K., Pugalenthi, G., Kandaswamy, K., Suganthan, P. N., Archunan, G. \& Sowdhamini, R. (2010). Bioinform. Biol. Insights, 4, 33-42.

Tanaka, T. \& Rabbitts, T. H. (2010). Nature Protoc. 5, 67-92.

Walter, T. S. et al. (2005). Acta Cryst. D61, 651-657.

Winn, M. D. et al. (2011). Acta Cryst. D67, 235-242. 